\title{
Opportunistic predation in tuna: a size-based approach
}

\author{
Frédéric Ménard*, Céline Labrune, Yunne-Jai Shin, Ah-Soy Asine†, \\ François-Xavier Bard $†$
}

Institut de Recherche pour le Développement (IRD), Centre de Recherche Halieutique Méditerranéen et Tropical (CRH), BP 171, 34203 Sètre Cedex, France

\begin{abstract}
To test whether predation is an opportunistic size-based process within a tuna community, analyses were carried out on the size composition of stomach contents of bigeye tuna Thunnus obesus (Lowe, 1839) and yellowfin tuna T. albacares (Bonnaterre, 1788) caught in 1995 to 1997 during longline scientific surveys in the French Polynesian Exclusive Economic Zone (EEZ). Prey size distributions were compared with the size distribution of organisms collected by pelagic trawls carried out during the same programme. Relationships between prey size and predator size were studied using quantile regressions, and were related to tuna mouth-gape measurements. The results showed that mean and maximum sizes of prey increased with increasing predator size, and that maximum prey sizes (versus tuna size) were below those predicted by tuna mouth-gape size. Minimum prey size varied little with tuna size, and the size distributions of prey in tuna stomachs were very asymmetrical (lognormal type), confirming that during growth, tunas continue to feed on small prey. Comparison with previous studies on other piscivorous species from different ecosystems underlined that tunas feed on very small prey in relation to their own size. However, comparison of size distributions of prey in stomach contents and prey in pelagic trawls revealed that bigeye tuna select larger prey than yellowfin tuna when such prey are available.
\end{abstract}

KEY WORDS: Tuna · Thunnus spp. · Size-based predation · Diet - Quantile regression

\section{INTRODUCTION}

Fish diets are frequently characterised by great diversity of prey species, which can be related to opportunistic predation. Fish predation is often described as an opportunistic (i.e. non-selective) process constrained by local prey availability and predatorprey size ratios (Shin \& Cury 2001, 2004). Size is indeed an important factor affecting trophic interactions in marine ecosystems, with most predators being larger than their prey (e.g. Sheldon et al. 1977, Smetacek 1999, Cury et al. 2003). To confirm that prey size and trophic level generally increase with increasing predatory fish size, analyses of stomach contents and nitrogen isotope ratio have been conducted on fish communities in different marine ecosystems (i.e. Scharf et al. 2000, Badalamenti et al. 2002, Jennings et al. 2002). In open-sea ecosystems, which are less productive than coastal ecosystems (Pauly \& Christensen 1995), tuna species represent a high biomass and are considered opportunistic predators in terms of prey species (e.g. Sund et al. 1981). The tunas' prey are micronekton organisms that exhibit different vertical behaviours in the water column, with most undertaking generally large vertical migrations during the twilight phases (Watanabe et al. 1999), but some remaining in the shallow layers both day and night (Marchal \& Lebourges 1996). Many studies have reported the size distribution and size range of tuna prey (e.g. Roger 1994), however empirical evidence of opportunistic size-based predation in tuna species has not been well studied. To our knowledge, the only study on sizebased predation focused on the size relationships between tunas and cephalopod prey (Rancurel 1976). 
In order to explore whether predation is an opportunistic size-based process for tropical tunas, the present study aimed at specifying the size distribution of the diet of 2 species, Thunnus obesus (Lowe, 1839) and T. albacares (Bonnaterre, 1788) in the French Polynesia EEZ, using trawling data and stomach content data collected during the ECOTAP programme (Abbes \& Bard 1999). Acoustic surveys, pelagic trawling and longline catches of tunas were carried out during the ECOTAP programme, with each data set involving specific bias. Bertrand et al. (1999, 2002a,b) combined these data in order to obtain complementary information about micronekton organisms in their environment, and characterised different types of nocturnal and diurnal scattering structures. They also proposed a typology of the micronekton distribution to predict tuna foraging on a regional scale (Bertrand et al. 1999), and described the pelagic trophic habitat of tunas (Bertrand et al. 2002a,b). The aim of the present study was to identify predation patterns in terms of predator and prey sizes. To this end, we reanalysed the trawling data and the stomach content data of yellowfin and bigeye tunas as a function of size. Firstly, the feeding habits of both tuna species were determined by analysing prey and predator size relationships by quantile regression. Secondly, predator-prey size ratios were determined to obtain an indication of the breadth of the tunas' trophic niche as a function of size. Finally, the size distribution of the prey in the tunas' stomachs was compared to that of micronekton sampled by trawling, and was related to tuna mouth-gape measurements to determine whether this limits the size range of prey ingested.

\section{MATERIALS AND METHODS}

Data. Data was collected within the framework of the ECOTAP programme (Abbes \& Bard 1999); the sampling design has been described by Bertrand et al. (2002a). Yellowfin Thunnus albacares and bigeye T. obesus tunas were caught from October 1995 to August 1997 in the French Polynesian EEZ, between 4 and $20^{\circ} \mathrm{S}$ and 134 and $154^{\circ} \mathrm{W}$, by instrumental longline fishing (Bach et al. 2003). Longlines were set to sample deep strata, i.e. from 100 to $400 \mathrm{~m}$, thus targeting mostly large tunas. Several small juveniles of both species were also caught by trolling. Tuna size was recorded as fork length, FL (cm) (see Table 1). The tunas were divided into 4 length classes in order to study potential changes during ontogeny. Stomachs were immediately removed from freshly caught fish, and the contents sifted and rinsed on ship deck. The stomach contents were fixed in $10 \%$ formalin onboard ship. In the laboratory, prey items were sorted into main prey classes (crustaceans, fishes, squids, gelatinous), which were then weighed (wet mass) to calculate their proportions in the tunas' diet. Prey sizes were measured according to prey morphology: standard length, SL (cm) for fishes, mantle length for squids, distance from eye to end of abdomen for crustaceans, and total length for gelatinous organisms. Highly digested prey were not measured. Assuming that prey height is more a constraint than length for a potential predator, we examined whether prey body height (and tuna mouth gape) limit the size of ingested prey. Only body lengths were available for our data set (no measure of prey body height), but Scharf et al. (1998b) estimated the relationship between fish height (defined as the maximum linear dorsoventral distance) and SL for several fish species, and from among those relationships, we selected their estimate for the butterfish Peprilus triacanthus, because this species has the largest height compared to its length. The SL of our fish prey were converted to height according to

$$
\mathrm{H}=\frac{(\mathrm{SL}-5.638)}{2.384}
$$

with $\mathrm{H}$ representing fish height (all measurements in mm; Scharf et al. 1998b). This ensured that a conservative hypothesis was tested, since it overestimated the height of the fish prey.

A total of 105 pelagic trawls were carried out during the ECOTAP programme with a fry pelagic trawl (5 mm mesh, mouth $18 \mathrm{~m}$ high) coupled with echosounding. The trawls were deployed according to nocturnal and diurnal scattering layers revealed by the echosounder: 69 trawls were conducted in diffuse and thick scattering layers during the night, and 36 trawls during the day for various forms of micronektonic aggregations; some organisms may have been collected during deployment and retrieval of the trawls. Most trawling was between the surface and intermediate layers $(\sim 250 \mathrm{~m})$, with 1 trawl extending below $400 \mathrm{~m}$ in depth. The biomass (weight) of the scattering layers was dominated by myctophids (see Bertrand et al. 2002a for more details). Samples were immediately frozen onboard ship. In the laboratory, micronekton organisms were sorted into the 4 main prey classes used for the stomach content analyses and counted and measured as for the tuna prey. All trawling data was combined in order to obtain a large-scale estimate of the size spectrum of the organisms sampled.

Data analysis. Scatter diagrams of raw data linking prey and predator body sizes typically comprise a variety of polygonal structures, suggesting that upper and lower size boundaries change at different rates (Blackburn et al. 1992, Scharf et al. 1998a). Therefore, analysing changes in the highest and lowest sizes may be more informative than analysing changes in the mean 
sizes (Cade et al. 1999). Cohen et al. (1993) showed that positive correlation between the body size of a predator and that of its prey is rarely high (and even negative in some cases), whereas upper boundaries of prey size tend to increase with predator size. Quantile regressions, as defined by Koenker \& Bassett (1978), are well adapted for estimating changes near the upper boundaries of data distributions (Scharf et al. 2000, Eastwood et al. 2001, Cade 2003, Juanes 2003). Quantile regression is an extension to quantiles of the least-absolute deviation regression, whereby $50 \%$ of the observations are less than and $50 \%$ are greater than the fitted line (Scharf et al. 1998a, Cade et al. 1999). The package 'quantreg' of $R$ available from the Comprehensive R Archive Network (http://lib.stat. cmu.edu/R/CRAN) was used in this study; it incorporates an estimation of the standard errors of the regression parameters. The choice of the quantiles used to represent upper and lower boundaries is subjective (Scharf et al. 1998a). Therefore, we first documented the variations in the slopes of the quantile regression according to quantiles ranging from 0.05 to 0.95 . Slope estimates were compared using an $F$-like test (a variant of the Wald test) proposed in the $\mathrm{R}$ package, whereby the linear predictors of the fits are all the same, but the specified quantiles are different. The null hypothesis is that the slope coefficients of the models are identical. Ordinary least-squares regressions were also performed to estimate the relationship between mean prey size and predator size. Furthermore, quantile regression of prey body height versus predator body size was compared to the ordinary leastsquares regression of predator mouth-gape size versus predator body size. For this latter analysis, data of mouth-gape size for bigeye and yellowfin tuna were pooled, since the mouth morphology of both species is similar. Trophic-niche breadth for each species was examined on a ratio scale, following the approach of Scharf et al. (2000). Quantile regressions (5th and 95th) were fitted to prey:predator size ratios versus predator sizes. Slopes between upper and lower limits were compared using an $F$-like test: a significant difference corresponding to a divergence (convergence) of the slopes indicates an increase (decrease) of the ratiobased trophic-niche breadth.

\section{RESULTS}

A total of 136 bigeye and 97 yellow fin tunas with non-empty stomachs were analysed (Table 1). Fishes and squid were the most important food source by wet weight, gelatinous organisms were less commonly preyed on by both tuna species, and crustaceans were significant in the yellowfin tuna diet only (Fig. 1). Diet composition as a function of size class did not reveal

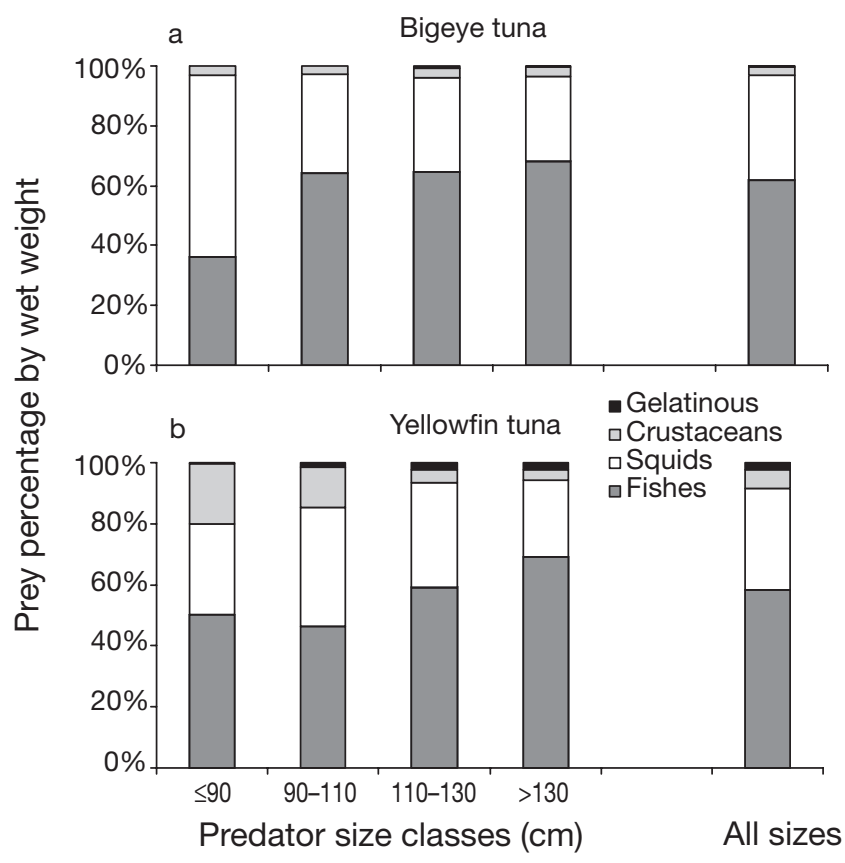

Fig. 1. (a) Thunnus obesus, (b) T. albacares. Contribution of main functional prey groups (fishes, squids, crustaceans, gelatinous organisms) to diet. Tunas are divided into 4 size classes (fork length)

Table 1. Thunnus albacares and T. obesus. Number and size descriptors (mean, minimum, maximum) of sampled tuna and number (n) and mean size of their prey. Tunas are divided into 4 size classes (fork length)

\begin{tabular}{|c|c|c|c|c|c|c|c|c|c|c|}
\hline \multirow[t]{2}{*}{ Parameter } & \multirow{2}{*}{$\leq 90 \mathrm{~cm}$} & \multirow{2}{*}{$90-110$} & \multicolumn{3}{|l|}{ T. obesus - } & \multicolumn{5}{|c|}{$T$. albacares } \\
\hline & & & $110-130$ & $>130 \mathrm{~cm}$ & Total & $\leq 90 \mathrm{~cm}$ & $90-110$ & $110-130$ & $>130 \mathrm{~cm}$ & Total \\
\hline Predator $\mathrm{n}$ & 18 & 65 & 46 & 7 & 136 & 14 & 14 & 57 & 12 & 97 \\
\hline Prey n & 184 & 974 & 650 & 90 & 1898 & 453 & 307 & 1152 & 201 & 2113 \\
\hline Mean prey size $(\mathrm{cm})$ & 5.66 & 6.67 & 6.92 & 7.86 & 6.71 & 2.60 & 3.23 & 4.26 & 4.95 & 3.82 \\
\hline \multicolumn{11}{|l|}{ Predator size $(\mathrm{cm})$} \\
\hline mean & & & 106.6 & & & & & 113.8 & & \\
\hline min. & & & 47 & & & & & 51 & & \\
\hline $\max$ & & & 159 & & & & & 147 & & \\
\hline
\end{tabular}


strong differences with tuna ontogeny. However, we did find that squid dominated the diet of small bigeye tuna ( $\mathrm{FL}<90 \mathrm{~cm}$; mean size $=75.2 \mathrm{~cm}$ ), whereas fishes dominated $(>60 \%)$ the diet of bigeye tuna larger than $90 \mathrm{~cm}$. Crustaceans were always present in a constant and small proportion in the diet of bigeye tuna. This latter prey group contributed $20 \%$ by wet weight to the diet of small yellowfin tuna ( $\mathrm{FL}<90 \mathrm{~cm}$; mean size $=76.1 \mathrm{~cm})$. However, the proportion of crustaceans regularly decreased in the larger size classes. Fishes remained the principal food source, especially for yellowfin tuna larger than $110 \mathrm{~cm}$. Overall, the differences in diet composition between bigeye and yellowfin tunas were not great, especially for tunas larger than $130 \mathrm{~cm}$, and we therefore investigated the relationship between prey size and predator size with no further consideration of the 4 prey groups.

Quantile regression parameters and their standard errors were estimated for a range of quantiles between 0.05 and 0.95 for both tuna species. The slope of the relationship between prey size and predator size changed according to the quantile used for prey length distributions (Fig. 2). The 5th and 95th quantiles were selected to estimate the lower and upper bounds of prey size distribution, respectively, for both tuna species. Maximum prey size increased as body size increased for both predator species, whereas minimum prey size did not exhibit a significant trend (Fig. 3). Table 2 shows the equations of the quantile and ordinary least-squares regressions. For both tuna species, the highest slopes were those for the upper boundary ( 0.127 and 0.091 for bigeye and yellowfin tuna, respectively), and the lowest corresponded to the lower boundary (slightly negative for bigeye tuna and slightly positive for yellowfin tuna). For each species,

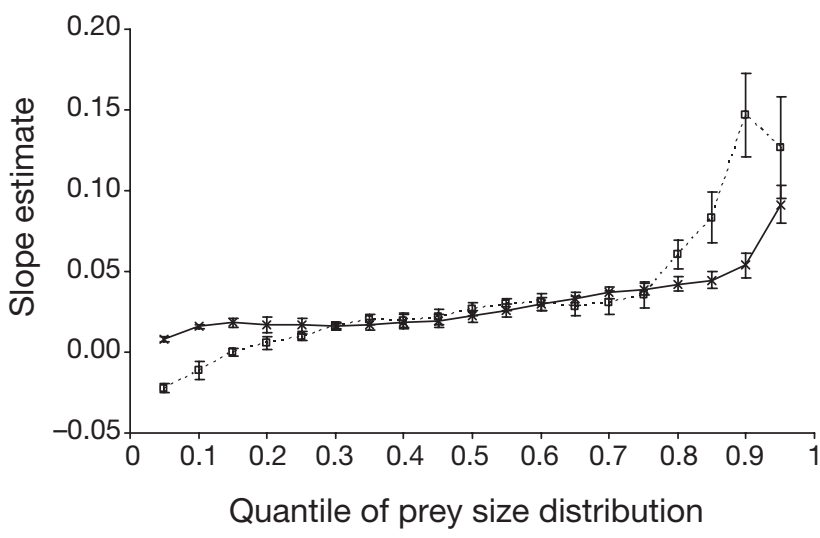

Fig. 2. Thunnus obesus and T. albacares. Estimates of quantile regression slopes $( \pm \mathrm{SE})$ for range of quantiles varying between 0.05 and 0.95 , for $T$. obesus (dashed line) and $T$. albacares (continuous line). These slope coefficients estimate different rates of change in quantiles of distribution of prey length conditional on predator length

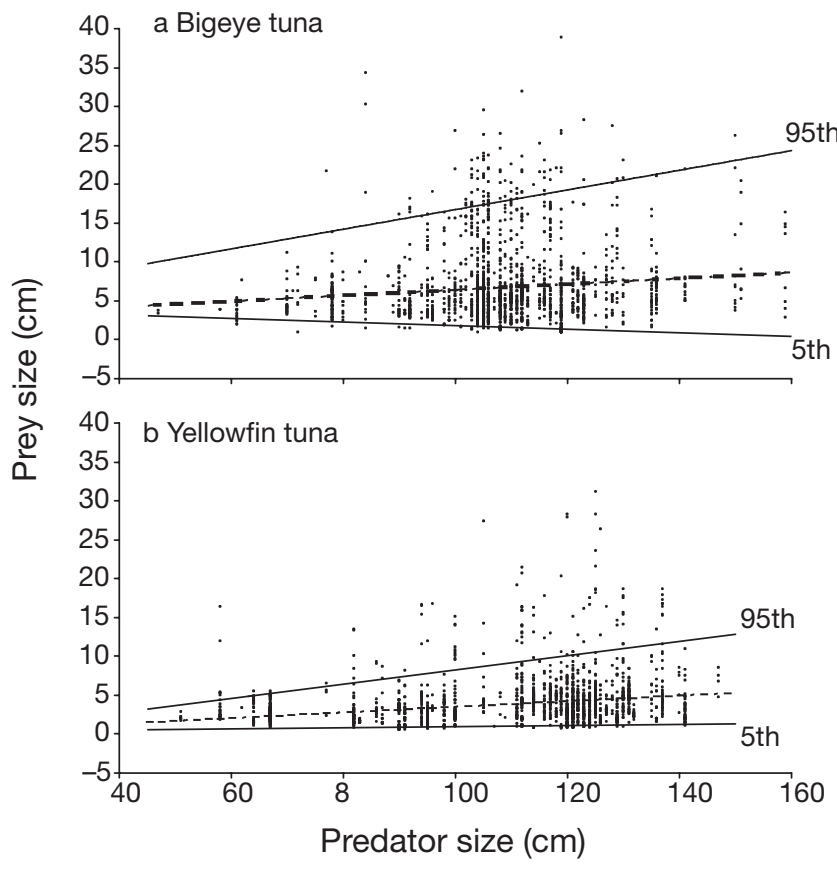

Fig. 3. (a) Thunnus obesus, (b) T. albacares. Predator-prey size scatter diagrams. Quantile regression lines (continuous lines) indicate upper (95th) and lower (5th) boundaries used to describe predator and prey size relationships. Leastsquares regression line (dashed line) estimates rates of

change in mean prey size as a function of predator size

the difference between the upper- and lower-boundary slopes was highly significant $(p<0.0001$ in both $F$-like tests). Mean prey size-predator size slopes estimated from ordinary least-squares regression were similar for both tuna species and significantly positive ( 0.037 and 0.036 for bigeye and yellowfin tuna, respectively). They were about 3 times lower than the upper boundaries of the corresponding quantile regressions, indicating that the ontogenetic changes in mean prey sizes were driven primarily by changes in maximum prey size. The higher intercept and slope values of the upper boundary for bigeye tuna indicates that, at equivalent sizes, bigeye tuna feed on prey of larger size than yellowfin tuna, and that the ontogenetic change in maximum prey size is larger for bigeye tuna. The distributions of prey sizes for each tuna size class corroborate this difference between the 2 species (Fig. 4). Larger bigeye tunas tend to feed on larger prey, while a progressive increase in the consumption of larger prey is less pronounced for yellowfin tunas. All these distributions were strongly asymmetrical (log-normal or gamma type), confirming the continued inclusion of small prey in the diet across the whole range of predator sizes.

We used 2 predictor variables for the measure of tuna mouth-gape size: maxillary length $\left(\mathrm{L}_{\mathrm{m}}\right)$ and inter-maxillary length $\left(\mathrm{L}_{\mathrm{im}}\right)$. Mouth-gape size $(\mathrm{cm})$ increased lin- 
Table 2. Thunnus obesus and T. albacares. Quantile regression equations (95th and 5th upper and lower boundaries, respectively) relating prey size to predator size, and least-squares equation fitted to same prey and predator size data. Standard error estimates of slope coefficients $\left(\mathrm{SE}_{\mathrm{s}}\right)$ and intercepts $\left(\mathrm{SE}_{\mathrm{i}}\right)$ are indicated

\begin{tabular}{|lcc|}
\hline 5th Quantile & 95th Quantile & Least-squares \\
\hline T. obesus & & \\
$y=-0.022 x+4.067$ & $y=0.127 x+4.067$ & $y=0.037 x+2.746$ \\
$\left(\mathrm{SE}_{\mathrm{s}}=0.006 ; \mathrm{SE}_{\mathrm{i}} 0.610\right)$ & $\left(\mathrm{SE}_{\mathrm{s}}=0.017 ; \mathrm{SE}_{\mathrm{i}} 1.669\right)$ & $\left(\mathrm{SE}_{\mathrm{s}}=0.008 ; \mathrm{SE}_{\mathrm{i}} 0.876\right)$ \\
T. albacares & $y=0.091 x-0.926$ & \\
$y=0.008 x+0.140$ & $y=0.036 x-0.110$ \\
$\left(\mathrm{SE}_{\mathrm{s}}=0.001 ; \mathrm{SE}_{\mathrm{i}} 0.049\right)$ & $\left(\mathrm{SE}_{\mathrm{s}}=0.018 ; \mathrm{SE}_{\mathrm{i}} 1.529\right)$ & $\left(\mathrm{SE}_{\mathrm{s}}=0.003 ; \mathrm{SE}_{\mathrm{i}} 0.367\right)$ \\
\hline
\end{tabular}
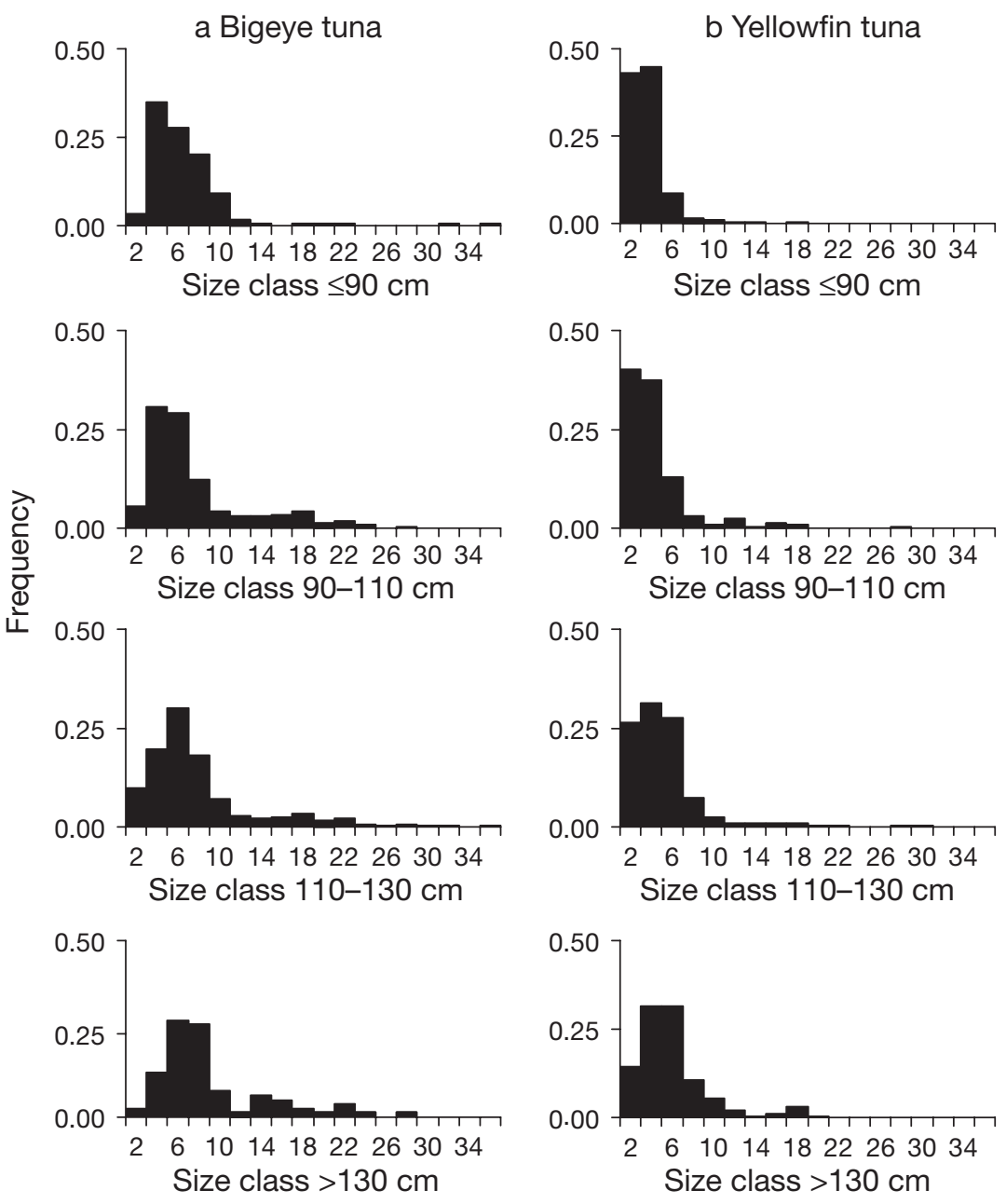

Fig. 4. (a) Thunnus obesus and (b) T. albacares. Size-frequency (n) distributions of prey $(\mathrm{cm})$ in stomach contents. Tunas are divided into 4 size classes (fork length)

early with increasing tuna fork length: $\mathrm{L}_{\mathrm{m}}=0.0823 \mathrm{FL}+$ 1.758, $\mathrm{n}=69, \mathrm{R}^{2}=0.95 ; \mathrm{L}_{\mathrm{im}}=0.0860 \mathrm{FL}+0.952, \mathrm{n}=126$, $\mathrm{R}^{2}=0.83$. These very close slope coefficients can be compared to the slope of the maximum prey body height estimated from the 95th quantile regression of fish prey body height $(\mathrm{H})$ versus tuna length $(\mathrm{H}=0.0246 \mathrm{FL}+$
4.603, Fig. 5). Mouth-gape size increased 3 to 4 times faster than the body height of fish prey, even when adopting a conservative hypothesis for the conversion of fish prey length to body height; thus, gape size does not seem to be the limiting factor of maximum prey size consumed by yellowfin and bigeye tuna.

Neither tuna species exhibited a significant ontogenetic change in trophicniche breadths, estimated from quantile regressions fitted to prey:predator size ratios versus predator sizes (Table $3 \&$ Fig. 6). Tests of equality of slope coefficients between upper (95th quantile) and lower (5th quantile) limits were not significant $(F$-value $=0.725, \mathrm{p}>0.395$ for bigeye tuna; $F$-value $=0.678, \mathrm{p}>0.411$ for yellowfin tuna). The use of other pairs of quantiles did not modify the results: neither convergence nor divergence was found in the slope coefficients, which were all close to zero.

Fig. 7 \& Table 4 compare the size distribution of organisms collected by trawling, and that of prey found in the tuna stomachs. Bigeye tuna fed on prey that were larger than the organisms sampled by trawling, as well as a significant amount of smaller prey, whereas the size distributions of the prey of yellowfin tuna and of trawl samples were very similar (in the range 0.5 to $9 \mathrm{~cm}$ ). Notwithstanding the selectivity of the trawl, these tuna species did exhibit an apparent difference in the selectivity for large prey compared to the prey available in the environment.

\section{DISCUSSION}

Body size is known to play a crucial role in predator-prey interactions, especially in aquatic ecosystems (Sheldon et al. 1977). Previous studies of predation by both marine and freshwater fishes have shown asymmetric prey size distributions and an increase in the range of prey size with increasing predator size (e.g. Mittelbach \& Persson 1998, Scharf et al. 2000). To our knowledge, no study has yet dealt specifically with tuna size-based predation in open-sea ecosystems, even though several studies have reported the size distribution or size range of tuna prey. Rancurel (1976) 


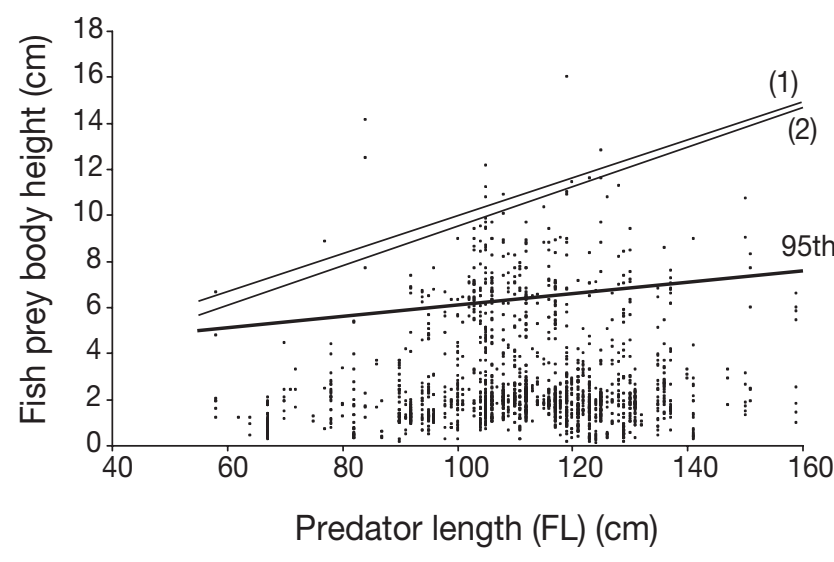

Fig. 5. Scatter diagram of predator (Thunnus spp.) size versus body height of prey estimated by conservative hypothesis (see 'Materials and methods'). Predator and prey data for Thunnus obesus and T. albacares are pooled. Lines (1) and (2) represent least-squares regressions of mouth-gape size versus predator size with gape size estimated from (1) maxillary length and (2) inter-maxillary length. Quantile regression line (thick line) indicates upper (95th) boundary used to describe relationship between predator size and body height of prey. FL: fork length

studied the size distribution of cephalopods consumed by tunas caught by longline, and showed that tunas did not systematically seek prey of a specific size. Our results indicate that the maximum size of the prey consumed by tunas tends to increase with increasing tuna body length, while the minimum prey size remains fairly stable. This is evidenced by the asymmetric prey size distributions that are roughly log-normally distributed. Thus, large tunas continue to consume large proportions of small prey. The slope coefficients of the upper bounds estimated by quantile regressions in Scharf et al. (2000) for 18 marine fish predators from continental shelf waters ranged from 0.077 to 0.894 (e.g. 0.435 for Atlantic cod Gadus morhua, for which body size varied between 21 and $150 \mathrm{~cm}$; 0.462 for bluefish Pomatomus saltatrix, a pelagic species in the

Table 3. Thunnus obesus and T. albacares. Quantile regression equations (95th and 5th for upper and lower boundaries, respectively) fitted to prey:predator size ratios to track potential changes in trophic-niche breadth. Standard error estimates of slope coefficients $\left(\mathrm{SE}_{\mathrm{s}}\right)$ and intercepts $\left(\mathrm{SE}_{\mathrm{i}}\right)$ are indicated

\begin{tabular}{|lc|}
\hline 5th Quantile & 95th Quantile \\
\hline T. obesus & \\
$y=-0.0005 x+0.071$ & $y=-0.0003 x+0.199$ \\
$\left(\mathrm{SE}_{\mathrm{s}}=0.00005 ; \mathrm{SE}_{\mathrm{i}}=0.0054\right)$ & $\left(\mathrm{SE}_{\mathrm{s}}=0.0002 ; \mathrm{SE}_{\mathrm{i}}=0.0239\right)$ \\
T. albacares & \\
$y=-0.00001 x+0.01064$ & $y=0.00015 x+0.06731$ \\
$\left(\mathrm{SE}_{\mathrm{s}}=0.00001 ; \mathrm{SE}_{\mathrm{i}}=0.00069\right)$ & $\left(\mathrm{SE}_{\mathrm{s}}=0.00019 ; \mathrm{SE}_{\mathrm{i}}=0.01873\right)$ \\
\end{tabular}

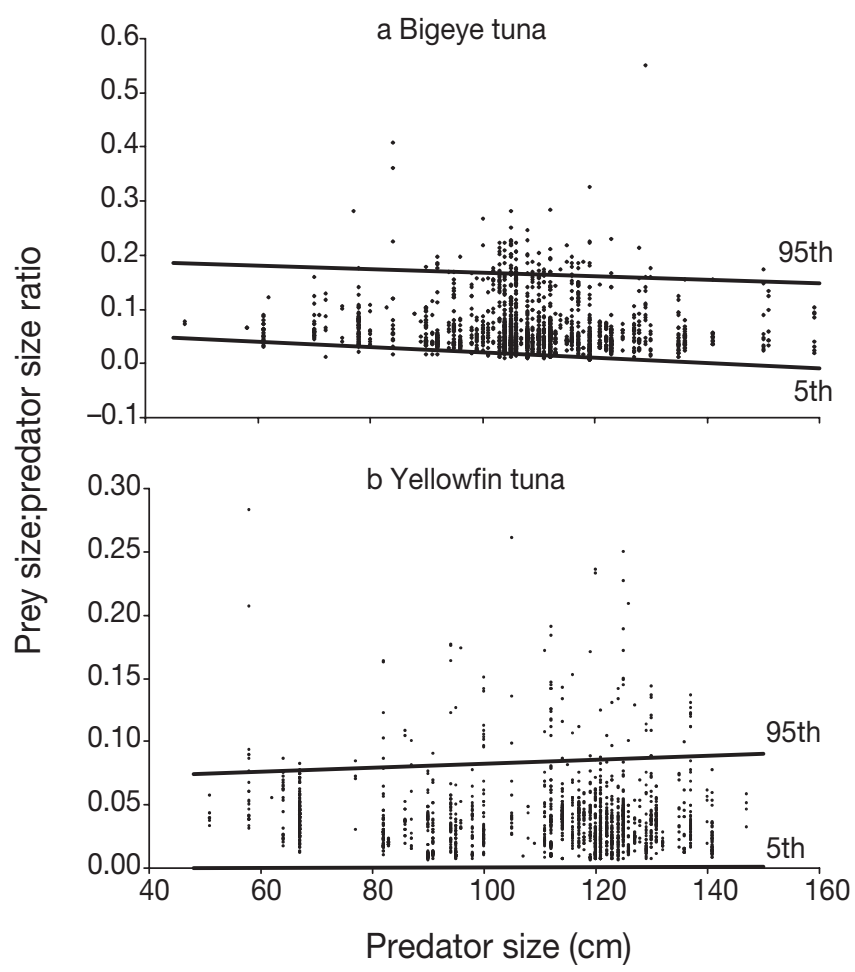

Fig. 6. Thunnus obesus and T. albacares. Scatter diagrams of relative prey size (prey:predator size ratio) as a function of predator size. Quantile regression lines (95th and 5th for upper and lower boundaries, respectively) indicate potential changes in trophic-niche breadth

size range 11 to $88 \mathrm{~cm}$ ). The upper-boundary slopes we estimated for bigeye and yellowfin tuna were 0.127 and 0.091, respectively. Compared with the values estimated by Scharf et al. (2000), both tuna species are within the category of predators that feed on prey with the smallest relative size. The trophic-niche breadth of bigeye and yellowfin tuna did not increase with increasing predator size: the prey size:predator size ratios did not change during ontogeny across the tuna size ranges considered in the present study. The absence of bias due to the increase of prey numbers with increasing predator size was checked-Spearman correlation coefficients were not significant $(p=$ 0.315 and 0.110 for bigeye and yellowfin tuna, respectively). The lack of significant changes in trophicniche breadth is consistent with results of previous studies, which focused either on larval and juvenile stages (Pearre 1986, Munk 1997) or on both juvenile and adult fishes (Scharf et al. 2000). We also observed that the largest prey did not necessarily occur in the stomach contents of the largest tunas, but the small number of large tunas in our data set make this observation tentative. The ratio minimum:maximum tuna size in our data set was ca. 3 for both species (Table 1). 


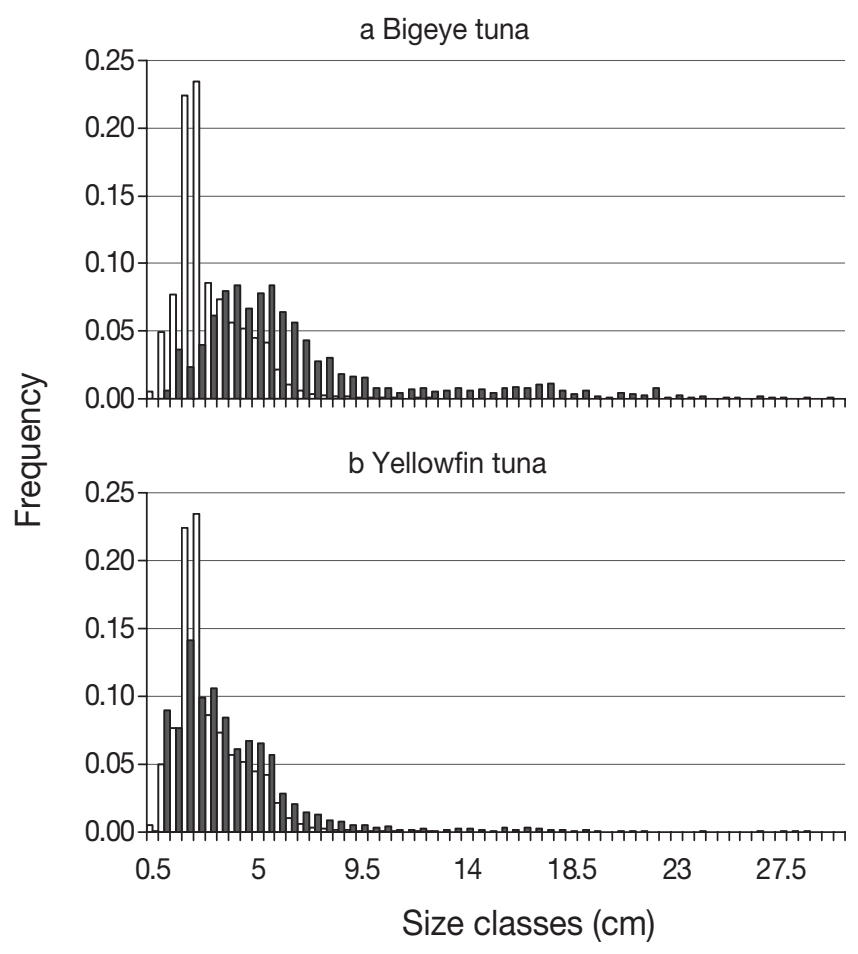

Fig. 7. (a) Thunnus obesus and (b) T. albacares. Size-frequency (n) distributions of organisms collected by trawling (white columns) and of prey found in stomach contents (black columns)

Table 4. Size $(\mathrm{cm})$ of organisms collected by trawling and of prey recovered from stomach contents of Thunnus obesus and T. albacares

\begin{tabular}{|lccc|}
\hline Size range & $\begin{array}{c}\text { Trawl } \\
\text { organisms }\end{array}$ & $\begin{array}{c}\text { T. obesus } \\
\text { prey }\end{array}$ & $\begin{array}{c}\text { T. albacares } \\
\text { prey }\end{array}$ \\
\hline Min. & 0.5 & 0.9 & 0.5 \\
Max. & 35.5 & 71.0 & 31.2 \\
Mean & 3.1 & 6.7 & 3.8 \\
Median & 2.5 & 5.2 & 3.0 \\
\hline
\end{tabular}

Samples of very small tunas were lacking, since specimens of $<50 \mathrm{~cm}$ are generally caught by purse seiners. We complemented our longline samples with trolling catches, which allowed us to study several small specimens of both species $(<90 \mathrm{~cm})$ but were not sufficient to cover a larger size range that would have enabled us to reinforce our interpretation of changes throughout their ontogeny. Furthermore, maturity may influence tuna diet. The gonadosomatic indexes (GSI) of females of both tuna species were recorded during the ECOTAP programme (Abbes \& Bard 1999). High values of GSI were observed for some of the bigeye tunas caught in the NE section of the French Polynesian EEZ during the first 2 quarters of the year, whereas low GSI values were always recorded for yellowfin tunas. The study area $\left(4\right.$ to $20^{\circ} \mathrm{S} ; 134$ to $154^{\circ} \mathrm{W}$ ) does not appear to be a main spawning area for either species. Thus, the influence of gonad development on diet was not considered.

The stomach content analyses were performed on deep-dwelling tunas caught by longline sets at great depths (Bach et al. 2003). The study of the diet of shallower tunas caught by surface purse-seine fishery might give different results. Indeed, several analyses have revealed symmetrical distribution in the prey size of shallow-water tunas. This difference in prey size distributions in tuna stomachs might be due to differences in prey size distributions in the tunas' environment. For example, Bard et al. (2002) showed that large yellowfin tuna caught by purse seiners in the equatorial Atlantic fed on monospecific concentrations of juvenile Cubiceps pauciradiatus belonging to the same size class. Ménard \& Marchal (2003) studied the foraging behaviour of tunas feeding on small schooling Vinciguerria nimbaria in the surface layer of the equatorial Atlantic. In both cases, concentrations of the schooling prey were dominant in the surface layer where tunas may seek their prey.

The body height of the prey as well as the mouth gape of the predator can limit the size of the prey consumed (Dennerline \& Van Den Avyle 2000, Scharf et al. 2000). In our study, only body length measurements of prey were available, and the largest prey eaten by both tuna species were mainly fishes. Therefore, we adopted a conservative hypothesis for the conversion of fish prey length to body height by using a published body height:body length relationship that certainly overestimated the height of the fish prey from our data set. Despite this conservative approach, maximum prey sizes were below those predicted by tuna mouthgape size. Our results provide important evidence that size-based feeding strategies of tunas may be related to limiting factors other than mouth-gape morphology, such as prey availability and behavioural differences of both predators and prey.

A slight difference was revealed between bigeye and yellowfin tunas, with bigeye tuna feeding on prey of larger relative sizes. This may be attributable to the different vertical distributions of the 2 tuna species arising from their respective physiological abilities (Brill 1994, Swimmer et al. 2004). Results of electronic tagging have shown that adult bigeye tuna are able to reach very deep layers, and that they usually make successive vertical, U-shape dives (e.g. Dagorn et al. 2000, Musyl et al. 2003). They can thus feed on organisms that remain at depth during the night, and forage in depth layers between 200 and $550 \mathrm{~m}$ during the day (Dagorn et al. 2000). On the other hand, adult yellowfin tuna spend most of their time in the surface layer, and 
consequently their diet is mainly composed of organisms present in the upper $100 \mathrm{~m}$ (Bertrand et al. 2002a). Thus both species have distinct foraging strategies, with bigeye tuna foraging over a wider area than the yellowfin tuna. We thus believe that bigeye tuna have access to a larger size range of prey in the environment. Bertrand et al. (2002a) have pointed out that bigeye tuna prey on myctophid aggregations as well as targeting the predators of myctophids, i.e. piscivorous fishes of larger size than myctophids. However, precise information on size distribution of the prey available in the environment is required to examine the selection of prey based upon predator size-prey size relationships. We used pelagic trawls for sampling the prey. The selectivity of the trawl on small organisms was probably not biased, whereas the frequency distribution of the larger sizes was flawed due to the escape behaviour of the large organisms (Fig. 7). Therefore, trawling data cannot reflect the full assemblage of prey in the environment, and it is thus difficult to separate the effects of prey type availability in the environment and active size selection by a predator. Bertrand et al (2002a) compared the proportions (by weight and by number) of various functional prey groups observed in trawls and in tuna stomachs, and interpreted the differences as differences in 'sampling efficiency'. Squid are in fact difficult to collect by nets, and cephalopod predators capture larger specimens and a greater diversity of species than does sampling gear (Rodhouse 1990, Cherel et al. 2004). In our trawl samples, squid were small and numerically fewest, whereas they contributed significantly to the diet of bigeye and yellowfin tunas. However, we believe that comparison of size data of prey from the stomach contents of predators and from pelagic trawls provides a reliable reflection of size-selection of prey by deep-dwelling tunas. Figs. $4 \& 7$ show that yellowfin tuna preyed on organisms in the same size range as those taken in the pelagic trawls, whereas bigeye tuna selected larger prey than yellowfin tuna, probably from deeper layers. Our results provide some evidence that tunas adopt opportunistic foraging behaviour, although there is an interspecific difference, with bigeye tuna selecting large prey when these are available.

Acknowledgements. We thank A. Bertrand and E. Bradbury for their wise and helpful comments, and 4 referees for their constructive comments and suggestions.

\section{LITERATURE CITED}

Abbes R, Bard FX (eds) (1999) Le programme ECOTAP, Etude $\mathrm{du}$ comportement des thonidés par l'acoustique et la pêche en Polynésie Française. Rapport Final. Convention Territoire-EVAAM-IFREMER-ORSTOM, No. 951070
Bach P, Dagorn L, Bertrand A, Josse E, Misselis C (2003) Acoustic telemetry versus monitored longline fishing for studying the vertical distribution of pelagic fish: bigeye tuna (Thunnus obesus) in French Polynesia. Fish Res 60:281-292

Badalamenti F, D'Anna G, Pinnegar JK, Polunin NVC (2002) Size-related trophodynamic changes in three target fish species recovering from intensive trawling. Mar Biol 141: 561-570

Bard FX, Kouamé B, Hervé A (2002) Schools of large yellowfin (Thunnus albacares) concentrated by foraging on a monospecific layer of Cubiceps pauciradiatus, observed in the eastern tropical Atlantic. Coll Vol Sci Pap ICCAT 54:33-41

Bertrand A, Le Borgne R, Josse E (1999) Acoustic characterisation of micronekton distribution in French Polynesia. Mar Ecol Prog Ser 191:127-140

Bertrand A, Bard FX, Josse E (2002a) Tuna food habits related to the micronekton distribution in French Polynesia. Mar Biol 140:1023-1037

Bertrand A, Josse E, Bach P, Gros P, Dagorn L (2002b) Hydrological and trophic characteristics of tuna habitat: consequences on tuna distribution and longline catchability. Can J Fish Aquat Sci 59:1002-1013

Blackburn TM, Lawton JH, Perry JN (1992) A method of estimating the slope of upper bounds of plots of body size and abundance in natural animal assemblages. Oikos 65: $107-112$

Brill RW (1994) A review of temperature and oxygen tolerance studies of tunas pertinent to fisheries oceanography, movement models and stock assessments. Fish Oceanogr 3:204-216

Cade BS (2003) A gentle introduction to quantile regression for ecologists. Front Ecol Environ 1:412-420

Cade BS, Terrell JW, Schroeder RL (1999) Estimating effects of limiting factors with regression quantiles. Ecology 80: 311-323

Cherel Y, Duhamel G, Gasco N (2004) Cephalopod fauna of subantarctic islands: new information from predators. Mar Ecol Prog Ser 266:143-156

Cohen JE, Pimm SL, Yodzis P, Saldana J (1993) Body sizes of animal predators and animal prey in food webs. J Anim Ecol 62:67-78

Cury P, Shannon LJ, Shin YJ (2003) The functioning of marine ecosystems: a fisheries perspective. In: Sinclair M, Valdimarsson G (eds) Responsible fisheries in the marine ecosystem. CABI Publishing, Cambridge, MA, p 103-123

Dagorn L, Bach P, Josse E (2000) Movement patterns of large bigeye tuna (Thunnus obesus) in the open ocean, determined using ultrasonic telemetry. Mar Biol 136:361-371

Dennerline DE, Van Den Avyle MJ (2000) Sizes of prey consumed by two pelagic predators in US reservoirs: implications for quantifying biomass of available prey. Fish Res 45:147-154

Eastwood PD, Meaden GJ, Grioche A (2001) Modelling spatial variations in spawning habitat suitability for the sole Solea solea using regression quantiles and GIS procedures. Mar Ecol Prog Ser 224:251-266

Jennings S, Warr KJ, Mackinson S (2002) Use of size-based production and stable isotope analyses to predict trophic transfer efficiencies and predator-prey body mass ratios in food webs. Mar Ecol Prog Ser 240:11-20

Juanes F (2003) The allometry of cannibalism in piscivorous fishes. Can J Fish Aquat Sci 60:594-602

Koenker R, Bassett G (1978) Regression quantiles. Econometrica 46:33-50

Marchal E, Lebourges A (1996) Acoustic evidence for unusual diel behaviour of a mesopelagic fish (Vinciguerria nimbaria) exploited by tuna. ICES J Mar Sci 53:443-447 
Ménard F, Marchal E (2003) Foraging behaviour of tuna feeding on small schooling Vinciguerria nimbaria in the surface layer of the equatorial Atlantic Ocean. Aquat Living Resour 16:231-238

Mittelbach GG, Persson L (1998) The ontogeny of piscivory and its ecological consequences. Can J Fish Aquat Sci 55: 1454-1465

Munk P (1997) Prey size spectra and prey availability of larval and small juvenile cod. J Fish Biol 51:340-351

Musyl MK, Brill RW, Boggs CH, Curran DS, Kazama TK, Seki MP (2003) Vertical movements of bigeye tuna (Thunnus obesus) associated with islands, buoys, and seamounts near the main Hawaiian Islands from archival tagging data. Fish Oceanogr 12:152-169

Pauly D, Christensen V (1995) Primary production required to sustain global fisheries. Nature 374:255-257

Pearre S Jr (1986) Ratio-based trophic niche breadths of fish, the Sheldon spectrum, and the size-efficiency hypothesis. Mar Ecol Prog Ser 27:299-314

Rancurel P (1976) Note sur les céphalopodes des contenus stomacaux de Thunnus albacares (Bonnaterre) dans le sud-ouest Pacifique. Cah ORSTOM Sér Océanogr 14:71-80

Rodhouse PG (1990) Cephalopod fauna of the Scotia Sea at South Georgia: potential for commercial exploitation and possible consequences. In: Kerry KR, Hempel G (eds) Antarctic ecosystems. Ecological change and conservation. Springer-Verlag, Berlin, p 289-298

Roger C (1994) Relationships among yellowfin and skipjack tuna, their prey-fish and plankton in the tropical western Indian Ocean. Fish Oceanogr 3:133-141

Scharf FS, Juanes F, Sutherland M (1998a) Inferring ecological relationships from the edges of scatter diagrams: comparison of regression techniques. Ecology 79:448-460

Editorial responsibility: Otto Kinne (Editor-in-Chief), Oldendorf/Luhe, Germany
Scharf FS, Yetter RM, Summers AP, Juanes F (1998b) Enhancing diet analyses of piscivorous fishes in the Northwest Atlantic through identification of original prey sizes from ingested remains. Fish Bull (Wash DC) 96:575-588

Scharf FS, Juanes F, Rountree RA (2000) Predator size-prey size relationships of marine fish predators: interspecific variation and effects of ontogeny and body size on trophicniche breadth. Mar Ecol Prog Ser 208:229-248

Sheldon RW, Sutcliffe Jr, Paranjape MA (1977) Structure of pelagic food chain and relationship between plankton and fish production. J Fish Res Board Can 34:2344-2353

Shin YJ, Cury P (2001) Exploring fish community dynamics through size-dependent trophic interactions using a spatialized individual-based model. Aquat Living Resour 14: $65-80$

Shin YJ, Cury P (2004) Using an individual-based model of fish assemblages to study the response of size spectra to changes in fishing. Can J Fish Aquat Sci 61:414-431

Smetacek V (1999) Revolution in the ocean. Nature 401:647

Sund PN, Blackburn M, Williams F (1981) Tunas and their environment in the Pacific ocean: a review. Oceanogr Mar Biol Annu Rev 19:443-512

Swimmer Y, McNaughton L, Moyes C, Brill R (2004) Metabolic biochemistry of cardiac muscle in three tuna species (bigeye, Thunnus obesus; yellowfin, T. albacares; and skipjack, Katsuwonus pelamis) with divergent ambient temperature and oxygen tolerances. Fish Physiol Biochem 30:27-35

Watanabe H, Moku M, Kawaguchi K, Ishimaru K, Ohno A (1999) Diel vertical migration of myctophid fishes (family Myctophidae) in the transitional waters of the western North Pacific. Fish Oceanogr 8:115-127

Submitted: June 21, 2005; Accepted: February 20, 2006

Proofs received from author(s): September 20, 2006 